\title{
Reduced Graphene Oxide Based Electrochemical Nonenzymatic Human Serum Glucose Sensor
}

\author{
Medha Gijare, ${ }^{1}$ Sharmila Chaudhari, ${ }^{2}$ Satish Ekar ${ }^{1}$ and Anil Garje ${ }^{3, *}$
}

\begin{abstract}
Present work proposes green synthesis of reduced graphene oxide using lemon peel extract(vitamin-c) and its application as an electrochemical nonenzymatic human serum glucose sensor. Improved modified Hummer's method was preferred for the preparation of graphene oxide. X-ray diffraction (XRD), Ultraviolet-visible absorption spectroscopy (UV-Vis) and X-ray photon spectroscopy (XPS) analysis revealed the successful reduction of Graphene oxide (GO) using lemon peel extract. Field emission scanning electron microscopy (FESEM), Fourier transform infra-red spectroscopy (FTIR) and Raman spectroscopy supports the formation of reduced graphene oxide ( $\mathrm{rGO}$ ) nanosheets. The proposed glucose sensor exhibits high sensitivity of 1402 $\mu \mathrm{A} \cdot \mathrm{cm}^{-2} \mathrm{mM}^{-1}(\mathrm{~S} / \mathrm{N}=3)$ along with correlation coefficient of 0.9887 and low detection limit of $0.011 \mu \mathrm{M}$. The sensor has detected glucose with RSD of $1.99 \%$ in human blood serum. The measured values are well agreed with the values obtained using professional glucose sensor used in hospitals.
\end{abstract}

Keywords: Green synthesis; Lemon peel extract; Reduced graphene oxide; Glucose sensor.

Received: 22 May 2021; Accepted: 25 June 2021.

Article type: Research article.

\section{Introduction}

Graphene named as a 'wonder material' due to its extraordinary properties is the thinnest and strongest material having high electrical and thermal conductivity. Graphene oxide (GO) is obtained from graphite oxide using various methods like mechanical exfoliation, chemical synthesis, chemical vapour deposition (CVD) ${ }^{[1]}$ etc. CVD is popular among them for large-scale production. In chemical synthesis toxic materials such as hydrazine hydrate or sodium borohydride are used as a reducing agent. These reducing agents may harm biological application. ${ }^{[2]}$ Due to ecologically unfriendly approach and hazardous chemicals used in thermal, chemical and electrochemical methods roused us to ponder some different technique for synthesis of reduced graphene oxide (rGO). Green synthesis using phytoextracts and bacteria are some other methods of synthesis of GO. Bacterial synthesis is carried out under ambient conditions and requires expertise. In the present study, GO is synthesized using improved modified Hummer's method. Green synthesis route is adopted to obtain rGO by using phytochemicals present in lemon peel. Lemon is a citrus fruit containing rich source of natural vitamin $\mathrm{C}$ and exceptional anti-oxidant as

\footnotetext{
I Baburaoji Gholap College, Pune, Maharashtra, India.

${ }^{2}$ Anantrao Pawar College, Pirangut, Pune, Maharashtra, India.

${ }^{3}$ Sir Parashurambhau College, Pune, India.

*Email: adgarje@gmail.com (A. Garje)
}

well as antibacterial activity. ${ }^{[3]}$ Lemon peels are by-products of lemon and research shows that they are an excellent source of bioactive compounds. ${ }^{[4]}$ During the production of fruit juice and other citrus products, the peel accumulates in the bulk. Fruit peels are usually discarded as wastes; however, they are very rich sources of Vitamin C, fiber, and many nutrients, including phenolics and flavonoids which are also good antioxidant agents and contain many phytochemicals. ${ }^{[5,6]} \mathrm{A}$ lemon peel is used as an eco-friendly and biologically safe reducing and caping agent in the synthesis of rGO. There several extractions methods are adopted in pharmaceutical industries like, Soxhlet extraction, drying, cold maceration etc. The cold maceration method is preferred to extract lemon peel due to its simplicity and effectiveness to preserve the properties of phytochemicals unaltered. Functionalized graphene with some metallic oxide shows extraordinary sensing properties. ${ }^{[7]}$ Furthermore, a green reduction is simple, eco-friendly and cost-effective. It has high electrical conductivity due to large amount of $\mathrm{sp}^{2}$ carbon atoms. Moreover, $\mathrm{rGO}$ is an extremely encouraging material as a biosensor due to its remarkable specific area $\left(\sim 2600 \mathrm{~m}^{2} / \mathrm{gm}\right)$ and high electrical conductivity $\left(103.3 \mathrm{Scm}^{-1}\right) \cdot{ }^{[8-10]}$ It has diversified applications in various areas such as Batteries, ${ }^{[1]}$ Biomedical, ${ }^{[12]}$ Supercapacitors, ${ }^{[13]}$ printable graphene electronics $^{[14]}$ gas sensor ${ }^{[15]}$ and biosensors. ${ }^{[16]}$ Glucose biosensors have extensive industrial, environmental and 
biomedical applications. In clinical medicine,these biosensors are used to monitor patients, blood glucose level to diagnose and treat diabetes. Diabetes is a metabolic disease that causes an abnormal blood sugar level, which consequently activates several metabolic pathways related to inflammation and apoptosis events. ${ }^{[17]}$ This disease has no cure thus far. Hence, patients with diabetes consistently need to monitor their blood glucose levels to avoid complications. Thus, developing a fast,sensitive and reliable biosensor to detect glucose is necessary. Electrochemical biosensors, especially those containing glucose oxidase (GOx), are the preferred devices for determining blood glucose due to their simplicity,selectivity, sensitivity and direct point care assays. ${ }^{[18]}$ However, challenges in the use of enzyme-based glucose biosensors remain because of the low efficiency of enzyme immobilisation on a solid electrode. To overcome this problem, many researchers have utilised nanomaterials with different structures and developed non-enzymatic glucose sensors. ${ }^{[19]}$ In the present case, reduced graphene oxide (rGO) is modified using Fluorine-doped Tin Oxide (FTO) substrates. rGO/FTO modified electrode was used as an enzyme-free biosensor to detect glucose concentration in an efficient way using Linear sweep voltammetry and cyclic voltammetry. An important part of this study was to evaluate sensitivity, selectivity, reproducibility, and stability with a low detection limit. Moreover, the green reduction method employed for the preparation of rGO is an inexpensive and eco-friendly way. The fabricated glucose biosensor was also used in an investigation of glucose level in the existence of obstructing substances in real human blood serum.

\section{Materials and Methods}

Graphite powder (98\%), Potassium permanganate $\left(\mathrm{KMnO}_{4}\right.$, $99 \%)$, Hydrogen peroxide $\left(\mathrm{H}_{2} \mathrm{O}_{2}, 30 \%\right)$, sulphuric acid $\left(\mathrm{H}_{2} \mathrm{SO}_{4}, 99.99 \%\right)$, Hydrochloric acid (HCL, 30\%), Phosphoric acid $\left(\mathrm{H}_{3} \mathrm{PO}_{4}, 85 \%\right)$, Polyvinyl alcohol (PVA, 99\%), Fluorinedoped Tin Oxide (FTO) substrates, D (+) glucose, dopamine, L-ascorbic acid, D (-) fructose, lactose were purchased from Qualigens fine chemicals, India. Deionised (DI) water was purchased from Sharad agencies, India. Phosphate buffer solution (PBS) was prepared in the laboratory using the standard method, and Lemons were purchased from a local market. All the chemicals are of AR grade and used without further purification.

\subsection{Preparation of GO}

Synthesis of GO was carried out by using modified Hummer's method. ${ }^{[20]}$ The graphite powder was added to $\mathrm{H}_{2} \mathrm{SO}_{4}$ and $\mathrm{H}_{3} \mathrm{PO}_{4}\left(9: 1\right.$ proportion) and stirred for $1 \mathrm{~h}$ at $100{ }^{\circ} \mathrm{C}$. Potassium permanganate was added during stirring process. For oxidation purpose, $\mathrm{H}_{2} \mathrm{O}_{2}$ was added into the mixture resulting in yellow color. Repeatedly washing with $5 \% \mathrm{HCl}$ and DI water along with centrifuge $(4000 \mathrm{rpm})$ causes complete removal of $\mathrm{SO}_{4}{ }^{2-}$. After drying at $60{ }^{\circ} \mathrm{C}$ for nearly $24 \mathrm{~h}$ the resultant product (rGO) was collected. ${ }^{[21]}$

\subsection{Preparation of Phytoextracts}

Fresh lemon were purchased from local market and cleaned using DI water. The lemon peels were blended with domestic blender and kept in DI water for cold maceration overnight. The mixture was then stirred for half an hour at $50^{\circ} \mathrm{C}$ followed by filteration. The stock was stored at $4{ }^{\circ} \mathrm{C}$ for further use.

\subsection{Reduction of GO using aqueous peel extract of lemon}

$50 \mathrm{mg}$ GO $(0.1 \mathrm{mg} / \mathrm{ml})$ was dispersed in DI via sonication for $45 \mathrm{~min}$. An aqueous peel extract of lemon $(10 \mathrm{ml})$ was added to the aqueous GO solution. This mixture was refluxed for $6 \mathrm{~h}$ at $90{ }^{\circ} \mathrm{C}$ until it changes to brown-blackcolor. The supernatant was centrifuged at 4000 revolutions per minute and dried at $100{ }^{\circ} \mathrm{C}$ in vacuum oven. ${ }^{[22]}$

\subsection{Preparation of $\mathrm{rGO/FTO} \mathrm{modified} \mathrm{electrode}$}

$10 \mathrm{mg}$ of rGO powder was dispersed in $5 \mathrm{ml}$ DI water and $5 \mu \mathrm{l}$ PVA using bath sonication for 30 minutes. $10 \mu 1$ of the suspension was drop casted on previously cleaned FTO substrate. Working area of the electrode was $1 \mathrm{~cm}^{2}$. The electrode was annealed at $250{ }^{\circ} \mathrm{C}$ and used for further electrochemical measurements.

\subsection{Mechanism of reduction of GO by lemon peel phytoextract}

Fig. 1 exhibits mechanism of reduction of GO by lemon peel phytoextract. The reduction of GO by the phytoextract may invent from the oxidized products such as flavonoids, polyphenols, tannis, terpenoids, saponins, etc. present in lemon fruit peel. ${ }^{[23]}$ These phytochemicals usually have a large binding affinity towards $\mathrm{O}_{2}$ functional groups to create their respective oxides and water molecules as its by-product. Flavonoid compounds show excellent antioxidation properties due to their ability to reduce to the phenolic hydroxyl group. The phenolic hydroxyl group may react with the oxygencontaining groups decorated on GO sheets by releasing water molecules. GO contains reactive species namely, hydroxyl, epoxide, and carbonyl species. ${ }^{[2]}$ When aqueous GO and lemon peel phytoextract was mixed, sonicated, and refluxed at $95{ }^{\circ} \mathrm{C}$, acidic polyphenols in phytoextract may react with epoxide fraction through nucleophilic reaction. It results in opening up carbon-oxygen bond. Similar nucleophilic attacks of polyphenols with the eradication of water molecules might be experienced by carbonyl and hydroxyl groups. The process results in the conversion of $\mathrm{GO}$ to $\mathrm{rGO}$, along with the production of black-colored graphene and its stable compounds.

The epitaxial growth process resulted in the formation of crumpled rGO nanosheets. A glucose sensing performance of $\mathrm{rGO} / \mathrm{FTO}$ modified electrode was studied in presence of phosphate buffer solution (PBS: $7.4 \mathrm{pH}$ ). Normally, when glucose disperses in PBS, it creates D-gluconolactone and hydrogen peroxide $\left(\mathrm{H}_{2} \mathrm{O}_{2}\right)$. It further generates D-gluconate with $\mathrm{H}^{+}$ions due to electro oxidation of glucose. Hence gluconolactone is the main product responsible for oxidation 


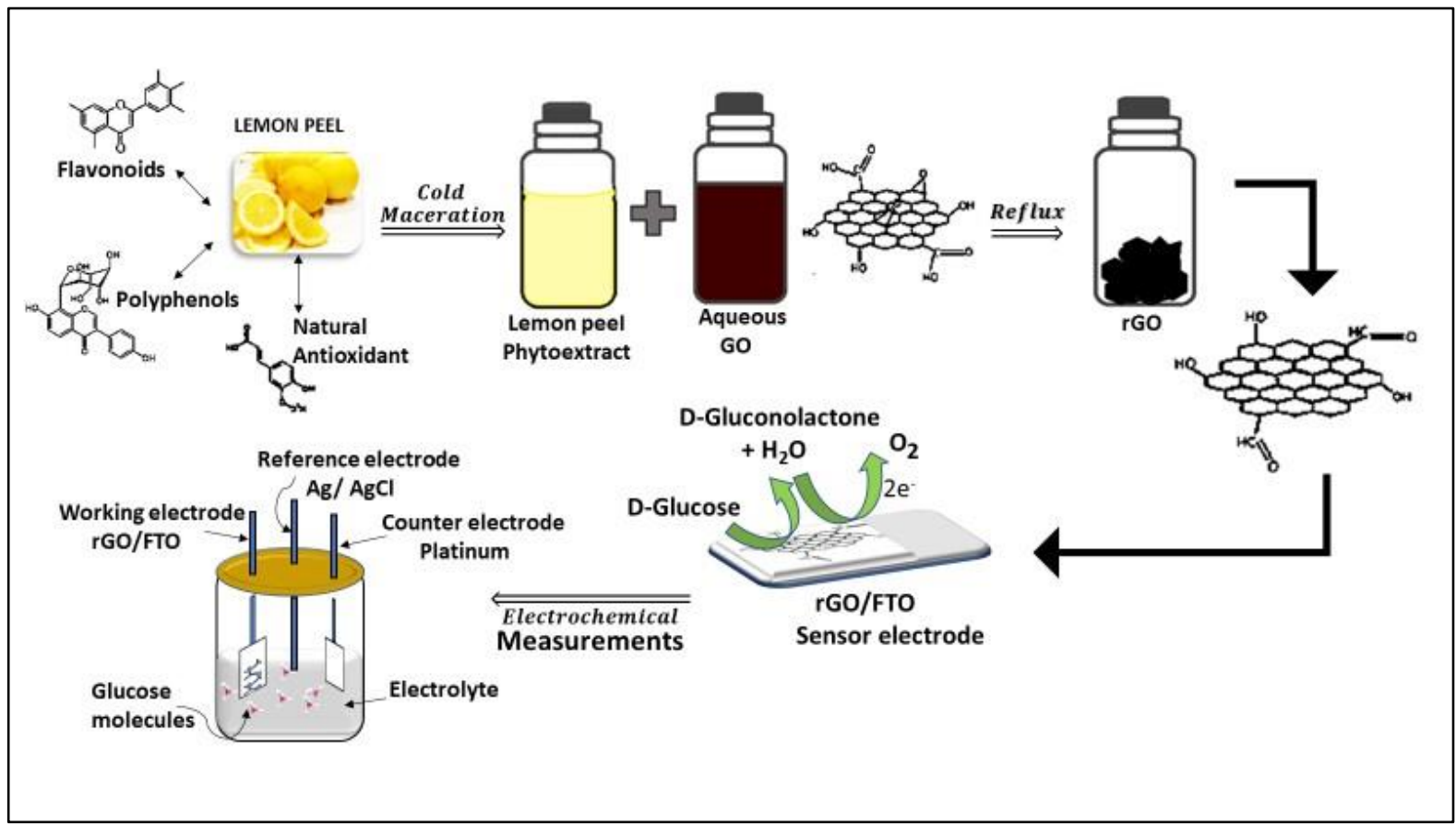

Fig. 1 Mechanism of green reduction of GO and rGO/FTO elctrode for glucose sensing.

that hydrolyses gluconic acid. $\mathrm{H}^{+}$ions reduce the pre-absorbed oxygen by releasing electrons which reduces barrier potential between consecutive grains and boosts the electrical conductivity. ${ }^{[25]}$ The probable chemical reaction may occur as, glucose $+\mathrm{O}_{2} \rightarrow \mathrm{H}_{2} \mathrm{O}_{2}+$ gluconic acid

\subsection{Structural and optical Characterization}

$\mathrm{X}$-Ray Diffraction (XRD) pattern of graphite powder, GO and rGO were taken using Phillips, Holland instrument $(\mathrm{CuK} \alpha$, $\left.1.542 \mathrm{~A}^{\mathrm{o}}, 5-85^{\circ}\right)$. The surface morphology and elemental composition of GO and $\mathrm{rGO}$ was done using field emission scanning electron microscope (FESEM: FEI Nova NanoSEM 450), Raman analysis was done by using raman spectrometer (Jobin-Yuon HR $800 \mathrm{UV}$ ) along with $\mathrm{He}-\mathrm{Ne}(633 \mathrm{~nm})$ laser source. The surface composition GO and rGO were analysed by multifunctional X-ray photoelectron spectroscopy (XPS) (ULVAC, PHI500 Versa Probe III with 1486.6 eV K_Al Xray source). Fourier Transform Infrared Spectroscopy (F)TIR study was done with FTIR-6100 spectrometer (JASCO) in the transmission $(\mathrm{T})$ mode in the wave number range $4000-500$ $\mathrm{cm}^{-1}$.

\subsection{Experimental set up for electrochemical measurements} Wonatech potentiostat was used in voltametric measurements for glucose detection along with three-electrode system, $\mathrm{rGO} / \mathrm{FTO}$, platinum and $\mathrm{Ag} / \mathrm{AgCl}$ as a working , counter and reference electrode respectively. These three electrodes were placed inside the beaker containing fixed volume of PBS as electrolyte. 150w Xenon lamp with illumination intensity of $100 \mathrm{~mW} / \mathrm{cm}^{2}$ was used to study I-V characteristics. The electrocatalytic performance of the electrode was studied using Linear Sweep Voltammetry (LSV) and Cyclic Voltammetry (CV).

\section{Results and Discussion}

\subsection{XRD analysis}

Fig. 2 illustrates XRD spectra of graphite, GO and rGO. The peak observed at $26.8^{\circ}(002)$ with a d-spacing value $0.335 \mathrm{~nm}$ (JCPDS file 75-1621) corresponds to the characteristic peak of hexagonal graphite. For GO, the characteristic peak at around $9.18^{\circ}(\mathrm{d} \sim 0.79 \mathrm{~nm})$ which may be ascribed to the existence of oxygen-rich groups on both sides of the sheets and water molecules trapped between the sheets. ${ }^{[26]}$ In case of rGO spectrum, a broad peak at $27.24^{\circ}$ along with $\mathrm{d} \sim 0.328$ $\mathrm{nm}$ confirms the complete formation of rGO. ${ }^{[27]}$

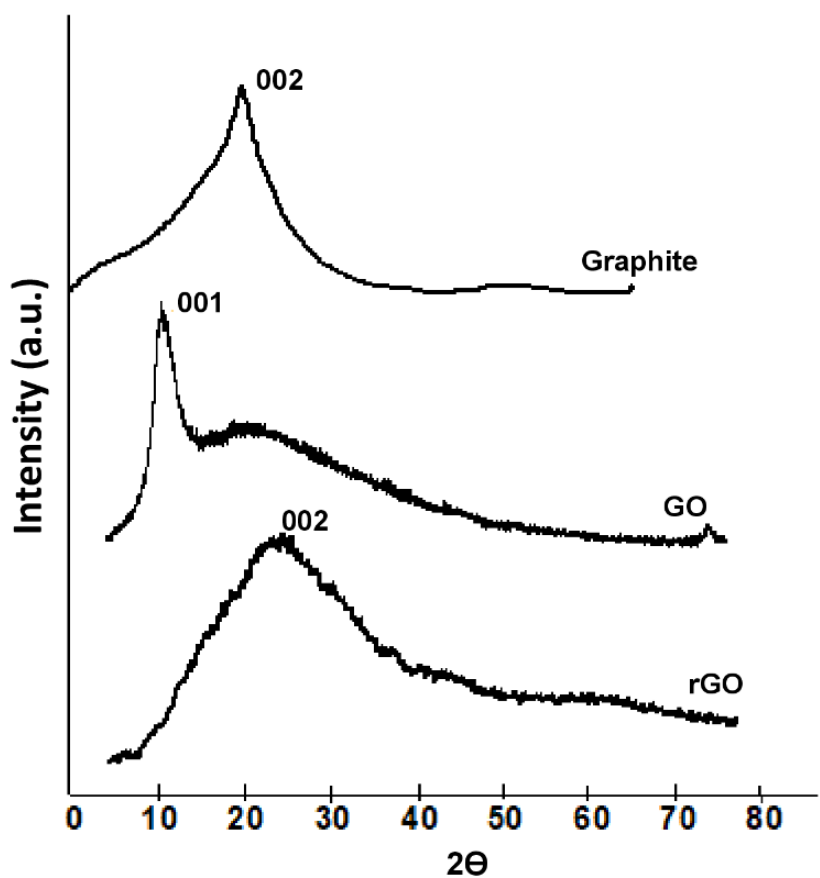

Fig. 2 XRD spectrum of graphite, GO and rGO. 


\subsection{UV-Vis spectra analysis}

Fig. 3 represents UV-Visible spectra of GO and rGO. GO showed two characteristic peaks at 225 and $303 \mathrm{~nm}$ that can be correlated to the electronic transition from $\pi-\pi^{*}$ and $n-\pi^{*}$ orbitals, respectively. ${ }^{[28]}$ The absorption peak at $228 \mathrm{~nm}$ is red shifted to $281 \mathrm{~nm}$ indicats that electronic conjugation within the reduced graphene oxide sheet is revived upon reduction of graphene oxide. ${ }^{[2,30]}$

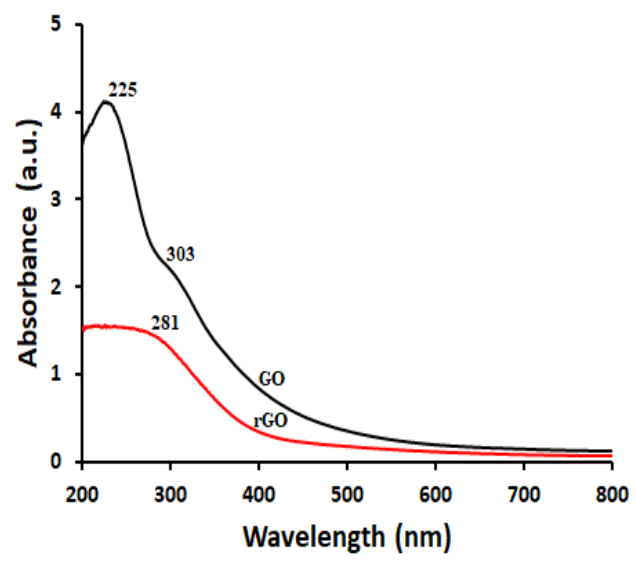

Fig. 3 UV-Visible spectra of GO and rGO.

\subsection{FESEM and EDS analysis}

Figs. 4(a) and (b) exhibits FESEM and EDS of GO and rGO. FESEM of GO shows wrinkled sheet like structure while for rGO, agglomeration of nanosheets along with irregular arrangement of stacked crumpled sheets was observed. This may be attributed to the nucleophilic reaction of flavonoids and polyphenols with the eradication of water molecules from carbonyl and hydroxyl groups during rGO synthesis.

\subsection{FTIR analysis}

FTIR spectra for GO and rGO is displayed in Fig. 5. The spectrum of GO exhibits a broad band at $3100-3500 \mathrm{~cm}^{-1}$ region due to the surface $\mathrm{O}-\mathrm{H}$ stretching vibrations or due to the absorbed water molecules. ${ }^{[31]}$ In addition to these, bands correspond to epoxide ring vibrations, $\mathrm{C}=\mathrm{O}$ stretching vibrations and $\mathrm{C}=\mathrm{C}$ stretching vibrations are visible at 1054 $\mathrm{cm}^{-1}, 1734 \mathrm{~cm}^{-1}$ and $1633 \mathrm{~cm}^{-1}$ respectively. A petite band ranging from 3200 to $3400 \mathrm{~cm}^{-1}$ (O-H stretching vibration) is observed in rGO as shown in Fig. 5. It can be implicated that rGO thus contains less amount of $\mathrm{O}-\mathrm{H}$ group. A reduction in intensity of absorption of $\mathrm{O}_{2}$ functional groups is observed in rGO supports the reduction of GO using lemon peel extract.

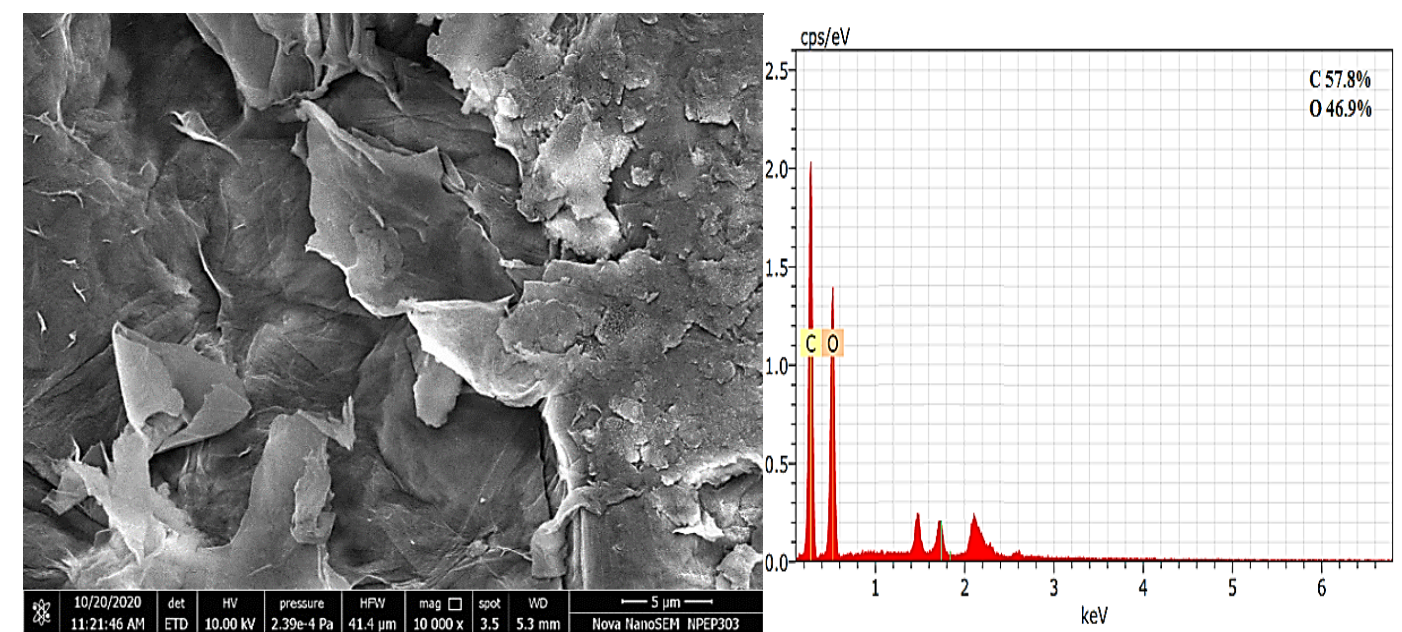

(a)

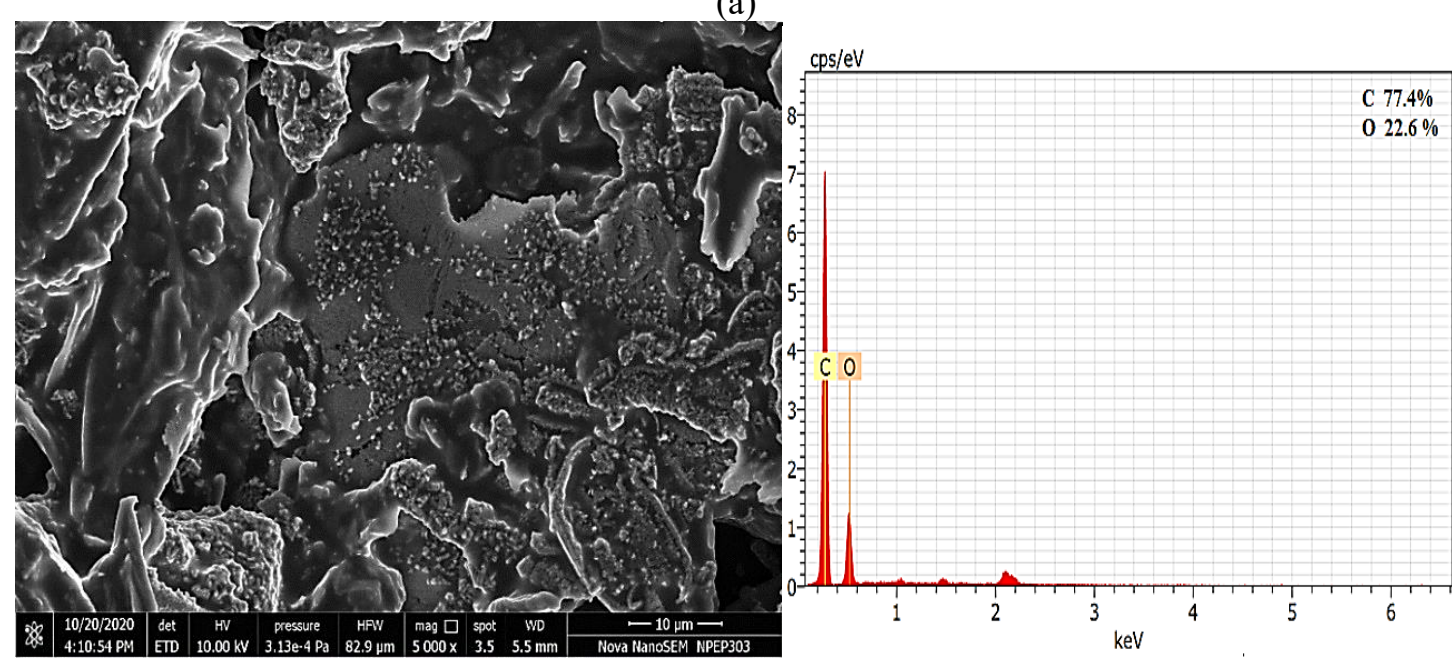

(b)

Fig. 4 FESEM and EDS of (a) GO and (b) rGO. 


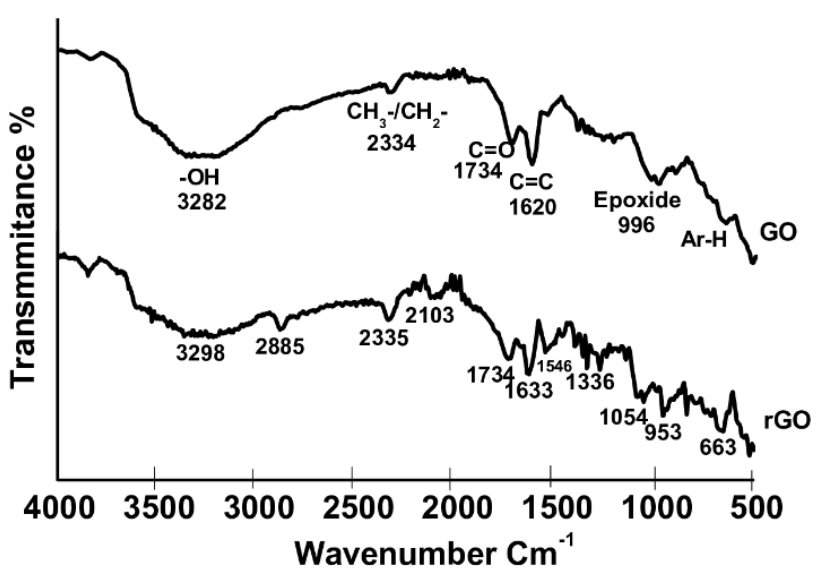

Fig. 5 FTIR spectrum of GO and rGO.

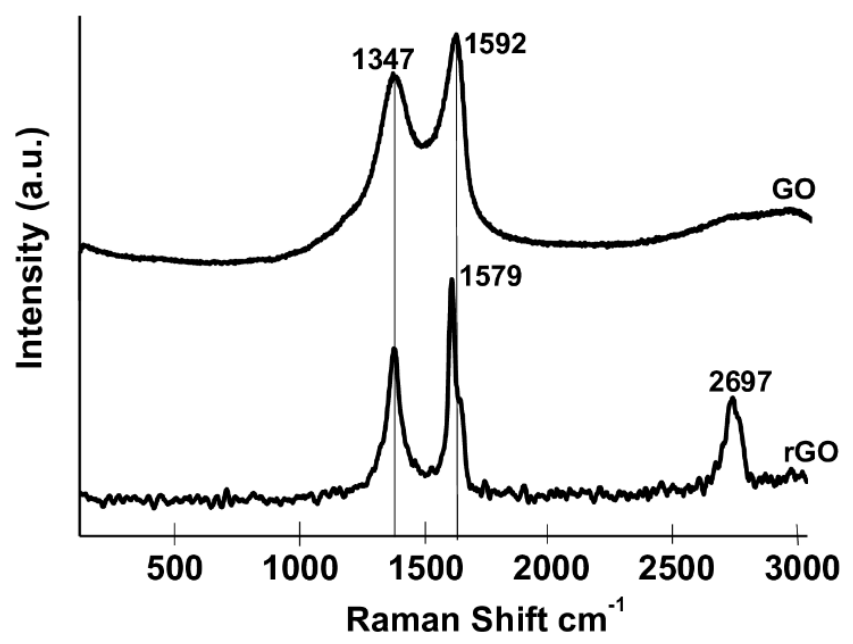

Fig. 6 Raman spectrum of GO and rGO.

\subsection{Raman spectroscopy}

Raman spectrum of GO and rGO is showcased in Fig. 6. The Raman spectrum of graphene is usually characterized by two specific modes of vibrations $G$ and D. G band represents the first-order scattering of the $E_{2 \mathrm{~g}}$ phonon of hexagonal $\mathrm{sp}^{2}$ carbon atoms and the $\mathrm{D}$ band is due to the breathing mode of k-point phonons of $A_{1 g}$ symmetry. ${ }^{[32]}$ The blue shift of $\mathrm{G}$ band is due to the reduction of $\mathrm{O}_{2}$ functional group during green reduction of GO. A decrease in $\mathrm{I}_{\mathrm{D}} / \mathrm{I}_{\mathrm{G}}$ ratio suggests an increase in the size of $\mathrm{sp}^{2}$ domains and ordered crystal structure of rGO. ${ }^{[33]}$ Presence of $2 \mathrm{D}$ band at $2697 \mathrm{~cm}^{-1}$ strongly supports reduction of GO. ${ }^{[34]}$

\subsection{XPS analysis}

$\mathrm{C} 1 \mathrm{~s}$ spectra of rGO shows the reduction of GO using aqueous lemon peel extract and validates the removal of $\mathrm{O} 2$ functional group (Fig. 7). For GO sample, the $\mathrm{C} 1 \mathrm{~s}$ bands can be deconvoluted int three bands attributed to $\mathrm{C}-\mathrm{C}, \mathrm{C}=\mathrm{O}$ and $\mathrm{C}(\mathrm{O}) \mathrm{OH}$ bonds at $284.8,286.5$ and $288.5 \mathrm{eV}$, respectively. ${ }^{[35]}$ The $\mathrm{C} 1 \mathrm{~s}$ XPS spectrum of rGO shows a significant intensity decrease of $\mathrm{C}=\mathrm{O}$ and $\mathrm{C}(\mathrm{O}) \mathrm{OH}$ bands in comparison to that of $\mathrm{GO}$, indicating effective deoxygenation of GO after the reduction. However, after being reduced, the peak intensity of oxygen with functionalities was decreased sharply as shown in figure indicating effective deoxygenation of GO after the reduction. This finding proved the reduction of GO. For rGO sample, the peaks of $\mathrm{C}-\mathrm{C}, \mathrm{C}=\mathrm{O}$ and $\mathrm{C}(\mathrm{O}) \mathrm{OH}$ bands locate at 284.5, 285.4 and $283.7 \mathrm{eV}$, respectively. Thus, there are the shifts in binding energy values of these bands of rGO. These shifts may due to the change in chemical environment of carbon atoms after reduction. ${ }^{[36]}$ In addition, after reduction process, the surface $\mathrm{C} / \mathrm{O}$ atomic ratio increases from 2.12 to 5.57. These results show that the removal of oxygen containing groups of GO using aqueous peel extract of lemon as reduction reagent was relatively successful.

\subsection{Electrochemical nonenzymatic detection}

Figs. 8 (a-b) represents cyclic voltammograms in PBS (7.4 $\mathrm{pH})$ electrolyte solution to study the electrocatalytic activity of the modified electrodes. No faradaic peak was observed on the bare FTO in presence of glucose. A very low oxidation current was exhibited on bare GO/FTO at $+0.7 \mathrm{~V}$. A well defined glucose oxidation peak was observed for bare

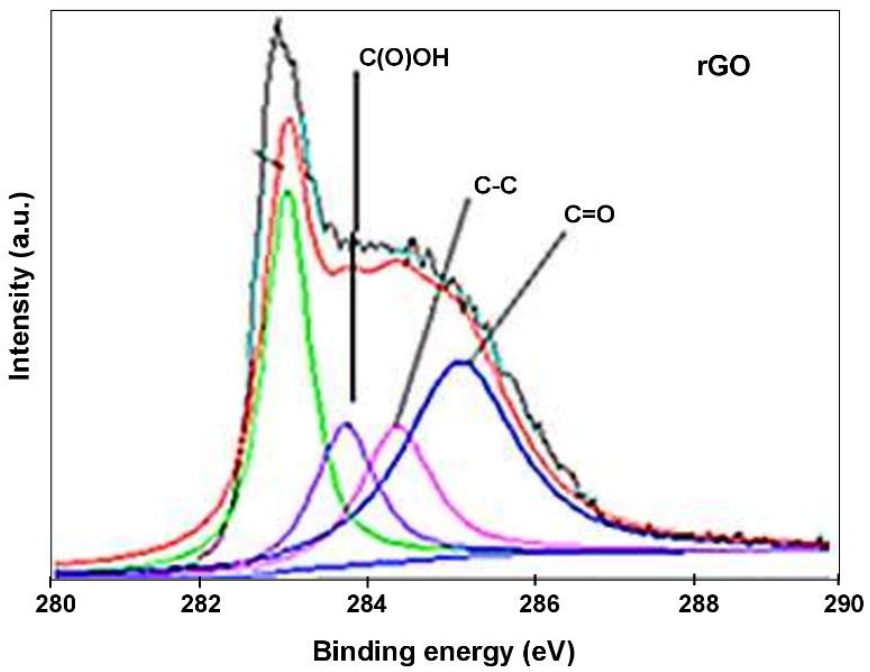

Fig. $7 \mathrm{C} 1$ s spectrum of $\mathrm{GO}$ and $\mathrm{rGO}$. 

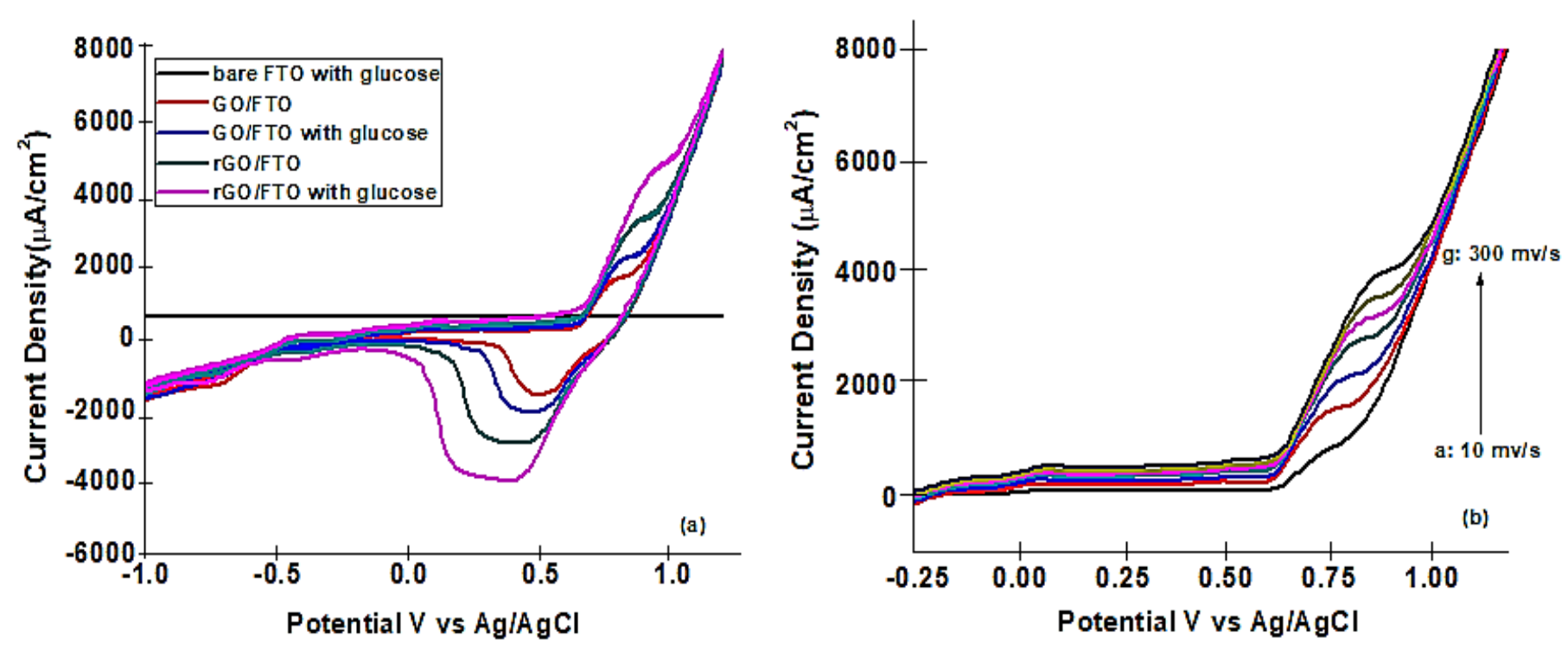

Fig. 8 (a) Cyclic Voltammogram of various electrodes at $100 \mathrm{mv} / \mathrm{s}$ scan rate and (b) LSV: effect of variable scan rate on rGO/FTO electrode.

rGO/FTO in presence of $1 \mathrm{mM}$ glucose compared to bare $\mathrm{rGO} / \mathrm{FTO}$. The oxidation current of $\mathrm{rGO} / \mathrm{FTO}$ is greater $(\sim 340$ $\mu \mathrm{A})$ than $\mathrm{GO} / \mathrm{FTO}$ at $+0.7 \mathrm{~V}$.This indicates that $\mathrm{rGO}$ is necessary to obtain high sensitivity and better electrocatalytic activity.

The rGO/FTO electrode was scanned from 10 to $300 \mathrm{mv} / \mathrm{s}$ in PBS $(7.4 \mathrm{pH})$ solution containing $1 \mathrm{mM} \mathrm{D}(+)$ glucose as shown in Fig. 8b. The applied potential was between $-0.5 \mathrm{~V}$ and $+1.2 \mathrm{~V}$, while oxidation occurred at $+0.7 \mathrm{~V}$ and peak current was increased with an increase in scan rate. The sensor electrode exhibited the maximum current flow and clear oxidation at $+0.7 \mathrm{~V}$. This indicates that electrochemical reaction takes place on $\mathrm{rGO} / \mathrm{FTO}$ nanocomposite electrode demonstrating its ability towards enzyme sensing. The cyclic voltammogram of rGO/FTO electrode exhibited a linear increase in current density with the increase in glucose concentration as shown in Fig. 9a. The time taken to obtain a stable response was $\sim 5 \mathrm{~s}$.

The possible mechanism of oxidation of glucose is as follows: During, electrooxidation of glucose in PBS, Dgluconolactone and hydrogen peroxide $\left(\mathrm{H}_{2} \mathrm{O}_{2}\right)$ generated Dgluconate with $\mathrm{H}^{+}$ions. The gluconolactone hydrolysed gluconic acid and $\mathrm{H}^{+}$ions reduced the pre-absorbed oxygen by releasing electrons. This revealed that the electron transport between PBS solution and electrode in the redox process was enhanced due to the high electrical conductivity and electrocatalytic activity of the rGO.
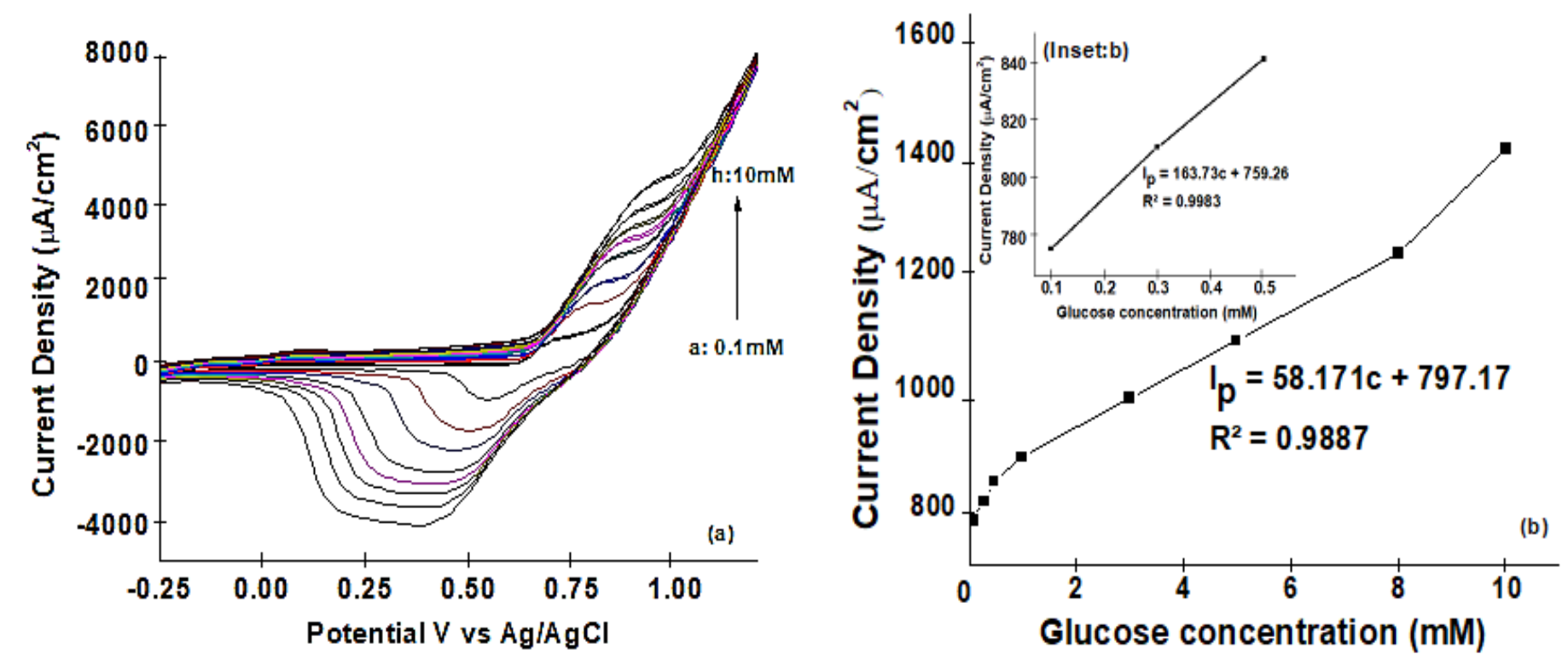

Fig. 9 (a) Cyclic Voltammogram of rGO/FTO with variable glucose concentration at $100 \mathrm{mv} / \mathrm{s}$ scan rate and (b) Calibration curve. 
Table 1. Comparison of the enzyme free glucose sensor based on rGO and its composites.

\begin{tabular}{|c|c|c|c|c|c|}
\hline Electrode & $\begin{array}{l}\text { Detection Potential } \\
(\mathrm{V}) \\
\end{array}$ & $\begin{array}{c}\text { Sensitivity } \\
\left(\mu \mathrm{A} / \mathrm{mM} \mathrm{cm}^{2}\right)\end{array}$ & $\begin{array}{l}\text { Detection range } \\
(\mathrm{mM}) \\
\end{array}$ & $\begin{array}{l}\text { Detection limit } \\
(\mu \mathrm{M}) \\
\end{array}$ & Ref. \\
\hline rGO & +0.7 & 1402 & $0.1-10$ & 0.011 & This work \\
\hline $\begin{array}{l}\text { Nafion/GOx/rGO-6/ZnONRs } \\
\text { /Au/PET }\end{array}$ & -0.8 to +0.8 & 2.26 & 11.5 & 37.5 & {$[37]$} \\
\hline Ni NPs/ATP/RGO & 0.0 to -1.5 & 1414.4 & $1-710 \mu \mathrm{M}$ & 0.37 & {$[38]$} \\
\hline $\mathrm{NiCo}_{2} \mathrm{O}_{4}$ anowrinkle-rGO & - & 548.9 & $0.005-8.6$ & 2 & [39] \\
\hline $\mathrm{AuPtNP} / \mathrm{rGO}$ & - & 48 & $0-2.4$ & 5 & [40] \\
\hline $\mathrm{rGO} / \mathrm{NiO}$ & - & - & 1 to 15 & 19.35 & [41] \\
\hline $\mathrm{CuO}(\mathrm{NP}) / \mathrm{rGO}$ & - & $4760( \pm 3.2)$ & - & $0.091( \pm 0.003)$ & [42] \\
\hline CuNWs/rGO/ITO & $+0.6 \mathrm{~V}$ & 9.3 & $0-5$ & - & {$[43]$} \\
\hline
\end{tabular}

Fig. $9 \mathrm{~b}$ represents oxidative current resopnse of $\mathrm{rGO} / \mathrm{FTO}$ electrode with variable glucose concentration $(0.1-10 \mathrm{mM})$. The calibration curve gives linear regression equation as $\mathrm{Ip}=$ $58.171 \mathrm{c}+797.17, \mathrm{R}^{2}=0.9887(\mathrm{~N}=8)$. The sensitivity of sensor electrode is calculated from slope of calibration curve.The sensor offered a sensitivity of $1402 \mu \mathrm{A} . \mathrm{mM}^{-1} \mathrm{~cm}^{-2}$ $(\mathrm{S} / \mathrm{N}=3)$. Similarly, inset:b shows oxidative current resopnse of rGO/FTO electrode with lower glucose concentration (0.1$0.5 \mathrm{mM}$ ). It gives the linear regression equation as $\mathrm{Ip}=163.73 \mathrm{c}$ $+759.26, \mathrm{R}^{2}=0.9983(\mathrm{~N}=3)$ along with a low detection limit of $0.011 \mu \mathrm{M}$. The performance analysis of the proposed sensor $(\mathrm{rGO} / \mathrm{FTO})$ in this work is compared with other enzymatic and non-enzymatic glucose sensors reported earlier are displayed in Table 1.

Electrochemical performance of $\mathrm{rGO} / \mathrm{FTO}$ sensor electrode is found to be superior in one or more parameters under consideration compared to other enzymatic and nonenzymatic glucose sensors presented in Table 1 .

\subsection{Selectivity, stability, and reproducibility}

The proposed biosensor was examined for the commonly occurring interfering species like ascorbic acid, dopamine, fructose, and lactose in human blood serum (Fig. 10a).

Selectivity: The biological range of glucose concentration in human serum is $3-8 \mathrm{mM}$, which is quite greater compared to other interfering substances like ascorbic acid, dopamine, fructose and lactose. Hence, the electrode responses were examined with $1 \mathrm{mM} \mathrm{D} \mathrm{(+)} \mathrm{glucose} \mathrm{with} \mathrm{above} \mathrm{mentioned}$ interfering species $(0.1 \mathrm{mM}$ each) in PBS (7.4) solution. The glucose sensing ability of proposed sensor was unaffected by the interefring species exhibited excellent selectivity of it.

Reproducibility: The reproducibility of the sensor was studied using 20 similar sensors. The current response was observed for $1 \mathrm{mM}$ glucose concentration in PBS buffer (7.4 $\mathrm{pH}$ ) for each sensor electrode using linear sweep voltammetry. The peak currents were noted and RSD was calculated mathematically. The reproducibility of the sensor was studied using 20 similar sensors electrodes. The current response was observed for $1 \mathrm{mM}$ glucose concentration for each sensor. RSD of $1.7 \%$ confirms the significant reproducibility.

Stability: The stability of sensor was studied by measuring current response for $1 \mathrm{mM}$ glucose concentration in PBS buffer $(7.4 \mathrm{pH})$ using linear sweep voltammetry for four weeks. The peak currents were noted after each week and RSD was calculated mathematically. The stability of the sensors was also tried and tested intermittently for a period of 4 weeks and yielded with RSD of $2.08 \%$ (Fig. 10b) which supports excellent stability of the proposed sensors. A repeatability of the proposed sensors was examined by measuring the current response for 5 times over 6 days and RSD of $1.57 \%$ was observed in performance as presented in Fig. 10c.

\subsection{Diagnosis of glucose in human serum}

The glucose concentration level in human blood samples was determined using proposed rGO based glucose biosensor. All human blood serum samples were collected from pathology laboratory of a renowned hospital. These samples were diluted (100 folds) using standard dilution method before analysis. However, the results obtained using proposed sensors were compared with the certified values received from pathology laboratory. The average recovery rate of $98 \%$ exhibits the reliability of the proposed sensor for human serum glucose biosensor application. Table 2 presents the experimental data for the human serum glucose concentration.

Table 2. Determination of glucose in human serum and its recovery.

\begin{tabular}{lllll}
\hline $\begin{array}{l}\text { Human } \\
\text { Serum } \\
\text { Samples }\end{array}$ & $\begin{array}{l}\text { Glucose } \\
\text { added } \\
(\mathbf{m M})\end{array}$ & $\begin{array}{l}\text { Glucose } \\
\text { recovered } \\
(\mathbf{m M})\end{array}$ & $\begin{array}{l}\text { Recovery } \\
\mathbf{( \% )}\end{array}$ & $\begin{array}{l}\text { RSD } \\
\mathbf{( \% )}\end{array}$ \\
\hline $\mathbf{1}$ & 0.2 & 0.195 & 97.5 & 2.5 \\
$\mathbf{2}$ & 0.5 & 0.496 & 99.2 & 0.8 \\
$\mathbf{3}$ & 1 & 0.98 & 98 & 2 \\
$\mathbf{4}$ & 3 & 2.92 & 97.33 & 2.66 \\
\hline
\end{tabular}




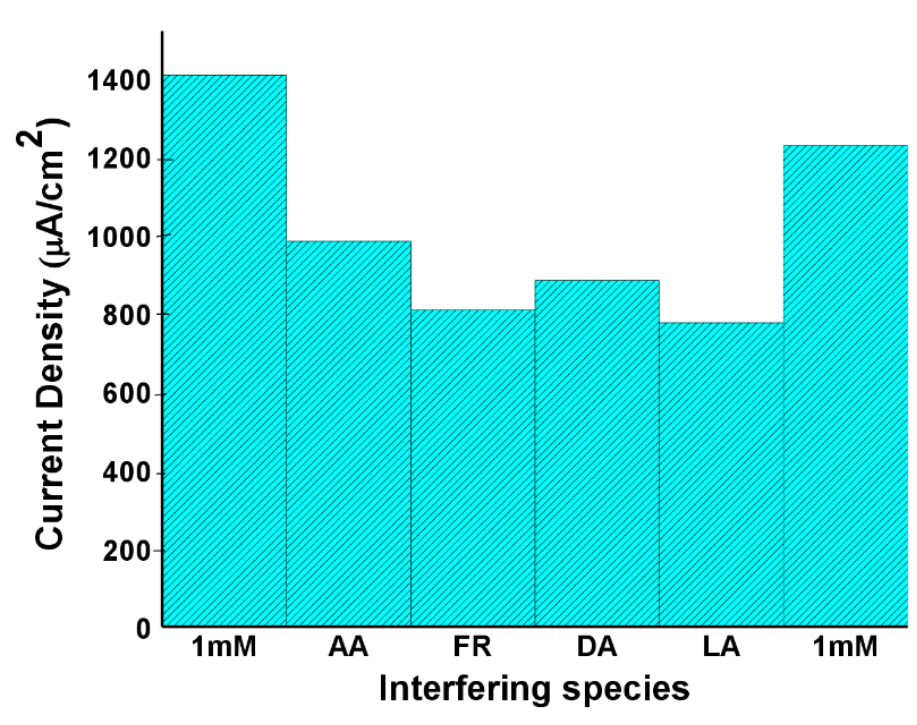

(a)

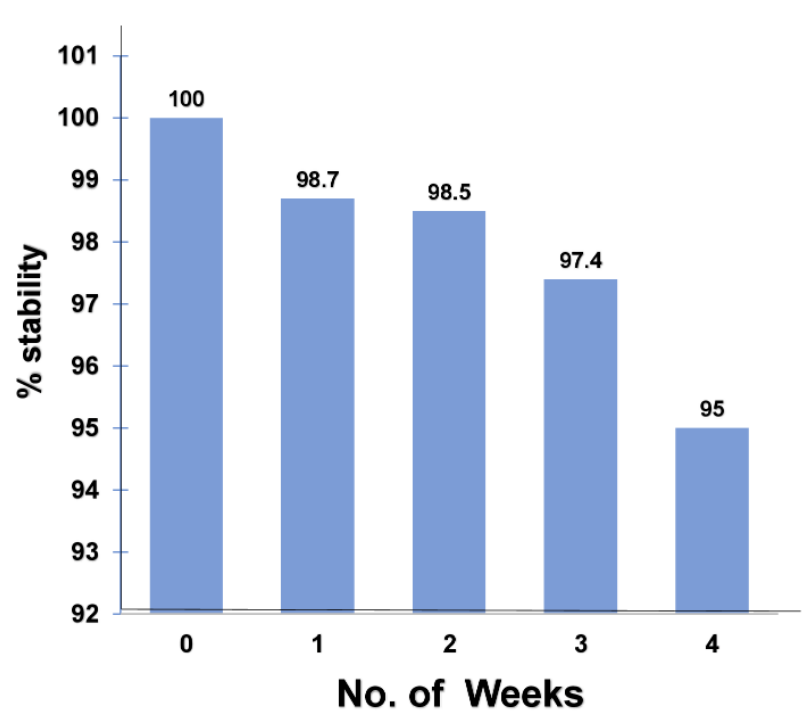

(b)

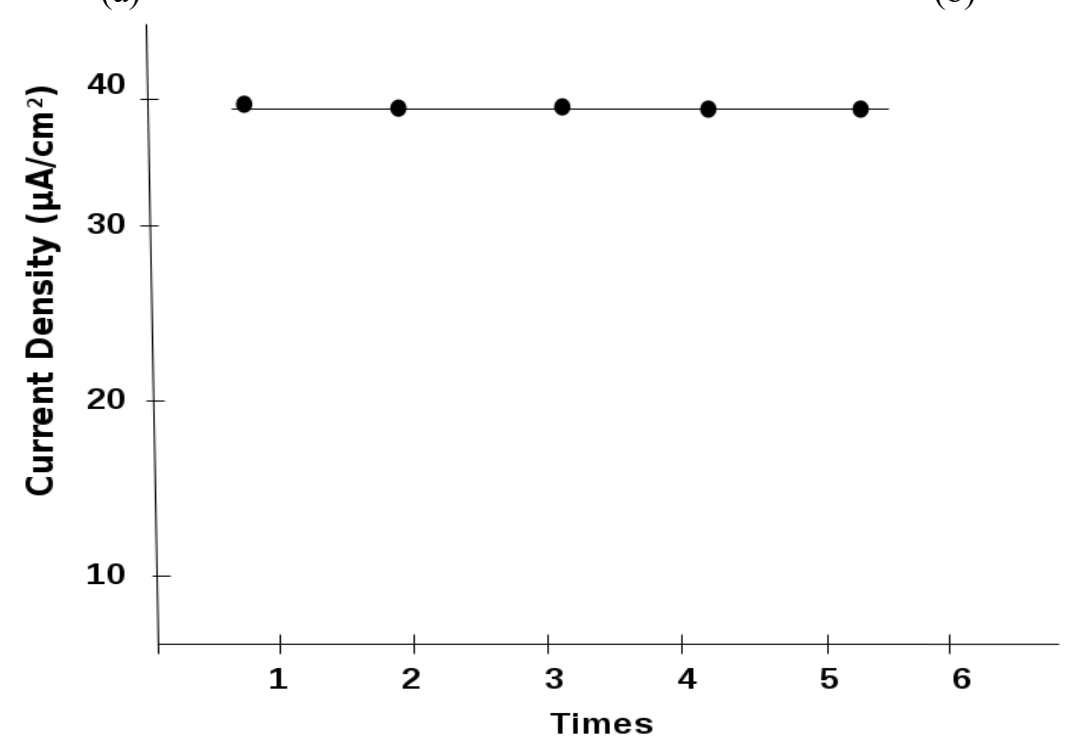

(c)

Fig. 10 (a) Selectivity (b) Stability (c) reproducibility of the rGO/FTO sensor electrode.

\section{Conclusion}

The lemon peel phytoextract is a promising candidate for the green reduction of GO. The eco-friendly approach, costeffectiveness, and simplicity in fabrication of $\mathrm{rGO} / \mathrm{FTO}$ electrode are some highlights of this work. The proposed biosensor has good stability, excellent reproducibility, and selectivity. It shows high sensitivity of 1402 $\mu \mathrm{A} . \mathrm{cm}^{-2} \mathrm{mM}^{-1}(\mathrm{~S} / \mathrm{N}=3)$ towards glucose in human serum along with correlation coefficient $\left(\mathrm{R}^{2}\right)$ of 0.9887 . The LOD of 0.011 $\mu \mathrm{M}$ makes it favorable for investigating glucose concentration in human serum samples. We believe that this work can introduce an emerging concept of rGO based functionalized nanomaterials to realize simple and reliable electrochemical glucose sensor platforms.

\section{Conflict of Interest}

There is no conflict of interest.

\section{Supporting Information}

Not applicable.

\section{References}

[1] M. J. Allen, V. C. Tung, R. B. Kaner, Chem. Rev., 2010, 110, 132-145, doi: 10.1021/cr900070d.

[2] G. Bhattacharya, S. Sas, S. Wadhwa, A.Mathur, J. Mc Laughlinc, S. Sinha Roy, RSC Adv., 2017, 7, 26680-26688, doi: 10.1039/C7RA02828H.

[3] A. Esmail Al-Snafi, IOSR J. Pharm., 2016, 6, 76-108, doi: 10.9790/3013-0680176108.

[4] Q. Mao, W. Jing, F. Zhou, S. Liu, W. Gao, Z. Wei, Z. Jiang, Mater. Sci. Semicon. Proc., 2021, 121, 105391, doi: 10.1016/j.mssp.2020.105391.

[5] Z. Shen, W. Gao, P. Li, X. Wang, Q. Zheng, H. Wu, Y. Ma, W. Guan, S. Wu, Y. Yu, K. Ding, Talanta, 2016, 169, 194-199, doi: 10.1016/j.talanta.2016.06.016. 
[6] G. Ma, M. Yang, C. Li, H. Tan, L.Deng, S. Xie, F. Xu, L. Wang, Y. Song, Electrochim. Acta, 2016, 22, 545-553, doi: 10.1016/j.electacta.2016.10.163.

[7] S. Stankovich, D. A. Dikin, G. H. Dommett, K. M. Kohlhaas, E. J. Zimney, E. A. Stach, R. D. Piner, S. T. Nguyen, and R. S. Ruoff, Nature, 2006, 442, 282-286, doi: 10.1038/nature04969.

[8] J. Samuel, R. Neale, P. Edward, Randviir, Ahmed S. Abo Dena, Craig E. Banks, Appl. Mater. Today, 2018, 10, 218-226, doi: 10.1016/J.IJPHARM.2020.119226.

[9] J. Feng, Y.Ye, M. Xiao, G. Wu, Y. Ke, Chem. Pap., 2020, 74, 3767-3783, doi: 10.1007/s11696-020-01196-0.

[10] R. Tarcan, O. Todor-Boer, I. Petrovai, C. Leordean, S. Astilean, I. Botiz, J. Mater. Chem. C, 2020, 8, 1198-1224, doi: 10.1039/C9TC04916A.

[11] M. Uceda, H-C. Chiu, R. Gauvin, K. Zaghib, G P. Demopoulos, Energy Storage Mater., 2020, 26, 560-569, 10.1016/j.ensm.2019.11.029.

[12] A. Mallick, A. S. Mahapatra, A. Mitra, J. Greneche, R. Ningthoujam, P. Chakrabarti, J. Appl. Phys., 2018, 123, 055103, doi: 10.1063/1.5009823.

[13] P. Hota, M. Miah, S. Bose, D. Dinda, K. Uttam Ghorai, Y. Su, S K. Saha, Mater. Sci. Technol., 2020, 40, 196-203, doi: 10.1016/j.jmst.2019.08.032.

[14] A. Hu, R. Li, D. Bridges, W. Zhou, S. Bai , D. Ma, P. Peng, J. Laser Appl., 2016, 28, 022602, doi: 10.2351/1.4944449.

[15] U.T. Nakate, S.P. Choudhary, R. Ahmed, P. Patil, Y.T. Nakate, Y.B. Hahn, Thomas S., Joshi N., Tomer V. (eds) Functional Nanomaterials. Materials Horizons: From Nature to Nanomaterials, Springer, Singapore, 2020, 303-328.

[16] S. Li, Q. Zhang, Y. Lu, D. Ji, D. Zhang, J. Wu, X. Chen, Q. Liu, Sensor Actuat B-Chem, 2017, 244, 290-298, doi: 10.1016/j.snb.2016.12.142.

[17] T. K. Prestgard, M. Tiwari, Mater. Sci. Eng. C, 2014, 41, 100-118, doi: 10.1016/j.msec.2014.04.013.

[18] D. Bruen, C. Delaney, L. Florea, D. Diamond, Sensors (Basel) , 2017, 17, 1866, doi: 10.3390/s17081866.

[19] M. Khan, V. Nagal, U. T. Nakate, M. R. Khan, A. Khosla and R. Ahmed, J. Electrochem. Soc., 2021, 168 067507, doi: 10.1149/1945-7111/ac030d.

[20] D. C. Marcano, D. V. Kosynkin, J. M. Berlin, A. Sinitskii, Z. Sun, A. Slesarev, L. B. Alemany, W. Lu, J. M. Tour, ACS Nano, 2010, 8, 4806-4814, doi: 10.1021/nn1006368.

[21] M. Gijare, S. Danane, M. Modak, A. Garje, JETIR, 2019, 6 , 1, http://www.jetir.org/papers/JETIRCP06003.pdf.

[22] M. Gijare, S. Chaudhari, A.Garje, JETIR, 2019, 6, 5, doi: 10.6084/m9.jetir.JETIRCP06036.

[23] D. Hou, Q. Liu, H. Cheng, H. Zhang, S. Wang, J. Solid State Chem., 2017, 246, 351-356, 10.1016/j.jssc.2016.12.008.

[24] J. Chattopadhyay, A. Mukherjee, C. E. Hamilton, J. Kang, S. Chakraborty, W. Guo, K. F. Kelly, A.R. Barron, W. E. Billups, J. Am. Chem. Soc., 2008, 130, 5414.

[25] Z. Wang, Y.Xiao, X. Cui, P. Cheng, B. Wang, Y. Gao, X. Li, T. Yang, T. Zhang, G. Lu, ACS Appl. Mater. Interfaces, 2014, 6, 3888-95, doi: 10.1021/am404858z.
[26] A. Lerf, A. Buchsteiner, J. Pieper, S.Schöttl, I. Dekany,T. Szabo, H. P. Boehm, J. Phys. Chem. Solids, 2006, 67, 1106-1110, doi: 10.1016/j.jpcs.2006.01.031.

[27] A. V. Murugan, T. Muraliganth, A. Manthiram, Chem. Mater., 2009, 21, 5004- 5006., doi: 10.1021/cm902413c.

[28] T. F. Emiru, D. W. Ayele,2017, Egypt. J. Basic Appl. Sci., 4, 74-79, doi: 10.1016/j.ejbas.2016.11.002.

[29] B. Vellaichamy, P. Periakaruppan, RSC Adv., 2016, 6, 88837-88845, doi: https://doi.org/10.1039/C6RA19834A.

[30] X. Wu, J. Zhou, W. Xing, G. Wang, H. Cui, S. Zhuo, Q. Xue, Z. Yana, S.Z. Qiao, J. Mater. Chem., 2012, 22, 23186-23193, doi: 10.1039/C2JM35278H.

[31] D. Suresh, P. C. Nethravathi, Udayabhanu, H. Nagabhushana, S.C. Sharma, Ceram. Int., 2015, 41, 4810-4813, doi: 10.1016/j.ceramint.2014.12.036.

[32] A. C. Ferrari, J. C. Meyer, V. Scardaci, C. Casiraghi, M. Lazzeri, F. Mauri, S. Piscanec, D. Jiang, K. S. Novoselov,S. Roth, A. K. Geim, Phys. Rev. Lett., 2006, 97, 187401, doi: 10.1103/PhysRevLett.97.187401.

[33] H. Gao, F. Xiao, C. Bun Ching, H. Duan, ACS Appl. Mater. Interfaces, 2011, 3, 3049-57, doi: 10.1186/s40543-021-00260-y. [34] M. S. Dresselhaus, A.Jorio, A. G. S. Filho, R. Saito, Philos. Trans. R. Soc., 2010, 368, 5355-5377, doi: 10.1098/rsta.2010.0213.

[35] S. Stankovich, D. A. Dikin, R. D. Piner, K. A. Kohlhaas, A. Kleinhammes, Y. Jia, Y. Wu, S. T. Nguyen, R. S. Ruoff, Carbon, 2007, 45, 1558, doi: 10.1016/j.carbon.2007.02.034.

[36] M. Jana, S. Saha, P. Khanra, N. C. Murmu, S. K. Srivastava, T. Kuila, J. H. Lee, Mater. Sci. Eng. B, 2014 ,186, 33, doi: 10.1016/j.mseb.2014.03.004.

[37] Q. Mao, W. Jing, F. Zhou, S. Liu, W. Gao, Z. Wei, Z. Jiang, Mater. Sci. Semicond. Process., 2021, 121, 105391, doi: 10.1016/j.mssp.2020.105391.

[38] Z.Shen, W.Gao, P. Li, X. Wang, Q. Zheng, H. Wu, Y. Ma, W. Guan, S. Wu, Y. Yu, K. Ding, Talanta, 2016, 159, 194-199, doi: 10.1016/j.talanta.2016.06.016.

[39] G. Ma, M. Yang, C. Li, H. Tan, L. Deng, S. Xie, F. Xu, L. Wang, Y. Song, Electrochim. Acta, 2016, 22, 545-553, doi: 10.1016/j.electacta.2016.10.163.

[40] X. Xuan, H. S. Yoon, J. Y. Park, Biosens. Bioelectron., 2018, 109, 75-82, doi; 10.1016/j.bios.2018.02.054.

[41] W. Alghazzawi, E. Danish, H. Alnahdi, M. A. Salam, Synth. Met., 2020, 267, 116401, doi: 10.1016/j.synthmet.2020.116401.

[42] S. Pourbeyram, J. Abdollahpour, M. Soltanpour, Mater. Sci. Eng.C, 2019, 94, 850-857, doi: 10.1016/j.msec.2018.10.034.

[43] V. K. Anand, R. Goyal, G. S. Virdi, International Conference on Advances in Computing, Communication \& Materials (ICACCM), 2020, 1, 105-109, doi: 10.1109/ICACCM50413.2020.9213041. 


\section{Author Information}

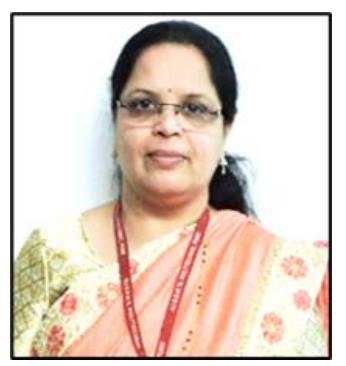

Mrs. Medha Gijare has obtained M.Sc. (Physics) Degree in 1993. She has successfully accomplished M.Phil. (2000) in Physics from University of Pune. She is actively engaged in teaching since 33 years. Presently she holds the position of selection grade lecturer in Physics at AISSMS's Polytechnic, Pune-01, Maharashtra, India. She is a research scholar of Baburaoji Gholap College, Sangvi, Pune27 Maharashtra, India. She is doing research in nanoscience and focused on designing and development of bio sensors. She has 07 research papers to her credit and presented many research papers at national and international conferences.

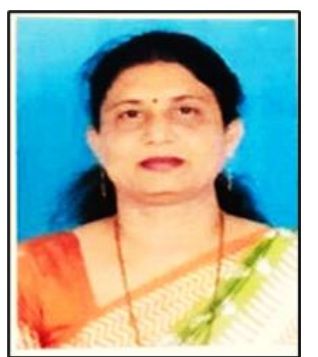

Dr Sharmila $R$ Chaudhari has huge teaching experience of 30 years, teaching up to post graduate classes and guiding research students for Ph.D and M.Phil. She has written e-book as reference book on sciyo.com on "Advanced Microwave circuits and systems" published by In tech publishers, Crocia Austria, Uk. She has presented 70 papers at various national and international conferences and published papers in the international reputed journals. She has many research projects under various funding agencies. She was ex-member of Senate and management council member of well-known university "Savitribai Phule Pune university" Presently, she holds the position of Principal, PDEA's Anantrao Pawar college, pirangut, Pune.

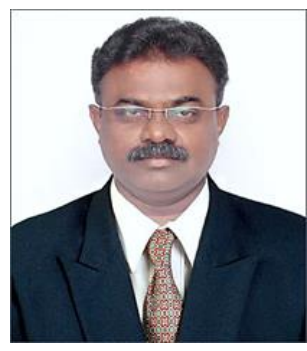

Dr. Satish Ekar is the Professor and researcher with 20+ years of experience teaching courses in both undergraduate and postgraduate levels. He has supervised $100+B S c$ theses and $30+$ MSc theses. He has published over 16 articles in peer-reviewed international journals and presented over $10+$ research articles in an international conference. He has received Teacher fellowship of University Grants Commission's during 2016 to 2018. His research areas include solid state nanostructured metal oxide gas sensors, dyesensitized solar cell, perovskite solar cells, super capacitors and water splitting. He has expertise in material characterization such as XRD, UV-Visible spectroscopy, XRay Photo electron spectroscopy, Scanning Electron Microscopy and Transmission Electron microscopy. Presently he holds the position of Professor and Head, Department of Physics, Baburaoji Gholap College, Sangvi, Pune-411027, Maharashtra, India.

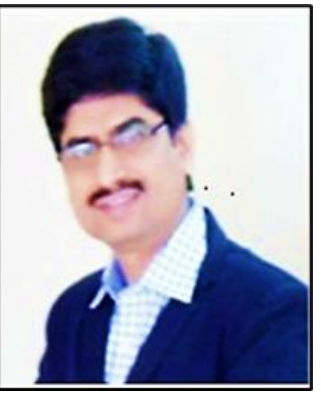

Dr. Anil Garje has obtained M.Sc. (Physics) Degree in 1993. He has successfully achieved M.Phil. (2001) and Ph.D. (2008) in Physics from University of Pune. He is actively engaged in teaching and research since last 20 years. Presently he holds the position of Assistant Professor in Physics at Sir Parashurambhau College Pune-30, India. His major field of research is material science and focused on designing and development of gas and bio sensors. He has 18 research papers to his credit and presented many research papers at national and international conferences. He is the winner of 'Young Scientist Award'given by International association of advanced materials, Spain.

Publisher's Note Engineered Science Publisher remains neutral with regard to jurisdictional claims in published maps and institutional affiliations. 